\title{
Biossegurança em saúde no ensino de ciências ${ }^{1}$
}

\section{Health biosafety in science teaching}

\author{
Marco Antonio Ferreira da Costa ${ }^{2}$ | costa@fiocruz.br \\ Maria de Fátima Barrozo da Costa ${ }^{3}$
}

\section{RESUMO}

Este texto, na forma de ensaio, discute a importância do Ensino de Ciências para as ações de Biossegurança em Saúde. Para tanto, contextualiza o campo da Biossegurança na vertente educativa e da sua profissionalização. Também questiona o papel da escola frente ao mundo do trabalho, e aponta para a necessidade da inserção de temas complexos nos currículos formais, e como o Ensino de Ciências, principalmente na pósgraduação, pode contribuir para uma melhor compreensão da Biossegurança em Saúde.

Palavras-chave: Ensino de Ciências; Biossegurança; Saúde.

\section{ABSTRACT}

This text, in the form of an essay, discusses the importance of Science Teaching to the Health Biosafety actions. To this end, we contextualize the Biosafety field in the educational aspect and it s professionalisation. Also questioning the role of the school facing the professional world and pointing out the need of adding complex issues in the formal curriculum, and how the Science Teaching, especially in postgraduate level, can contribute to a better understanding of Health Biosafety.

Key-words: Science Teaching; Biosafety; Health.

1 Palestra proferida no III Simpósio em Ensino de Ciências e Meio Ambiente do Rio de Janeiro/UNIFOA/Volta Redonda/RJ/2013

2 Doutor em Ciências, ênfase em Ensino de Ciências, pelo Instituto Oswaldo Cruz/Fiocruz/RJ; Professor da Escola Politécnica de Saúde Joaquim Venâncio/Fiocruz, e do Programa de Pós-Graduação em Ensino em Biociências e Saúde do Instituto Oswaldo Cruz/Fiocruz.

3 Doutora em Ciências, ênfase em Saúde Pública, pela Escola Nacional de Saúde Pública Sérgio Arouca (ENSP)/Fiocruz; Pesquisadora do Centro de Estudos de Saúde do Trabalhador e Ecologia Humana (CESTEH/ENSP)/Fiocruz. 


\section{INTRODUÇÃO}

Este texto, na forma de ensaio, aborda as relações da Biossegurança em Saúde, campo do conhecimento interdisciplinar, que ainda se encontra em uma fase pré-paradigmática, ou seja, a caminho de se tornar uma disciplina científica (FOUREZ, 1995), a partir da definição clara dos seus limites e conteúdos, com o Ensino de Ciências. A Biossegurança ainda não pode ser considerada uma ciência, exatamente pela falta de limitação dos seus domínios. Atualmente, ela é sustentada por várias ciências, como a Biologia, a Química, a Física, entre várias outras.

A Biossegurança possui múltiplos recortes e interfaces, principalmente éticos, cujos limites são amplos e estão em constante construção, e tem como princípios a promoção e a conservação da saúde ocupacional e da saúde planetária no contexto dos agentes de riscos químicos, físicos, biológicos, ergonômicos e psicossociais, além das questões pertinentes à Lei de Biossegurança ( $\mathrm{N}^{\circ} 11.105$ / 2005) que envolvem a moderna biotecnologia e ao uso de células-tronco embrionárias em pesquisas (COSTA e COSTA, 2012; BORBA et al., 2010; TEIXEIRA e VALLE, 2010).

Na área da saúde, aonde encontramos profissionais de nível básico, médio e superior, com perfis diversos e regidos por diferentes legislações, a inclusão da Biossegurança vem ocorrendo de forma tímida, em função até da sua própria complexidade. A maioria das ações educativas nesta área está contextualizada no âmbito não formal, isto é, as próprias instituições de saúde, como hospitais, laboratórios de saúde pública, hemocentros, por exemplo, projetam e executam cursos com as mais variadas estruturas, muitas vezes sem nenhuma base pedagógica, baseadas apenas nas experiências de seus profissionais, para atender, especificamente, suas necessidades atuais (COSTA e COSTA, 2004). Isso ocorre, a nosso ver, pela pouca expressividade da educação formal, principalmente nos cursos técnicos e superiores da área da saúde, em suprir as necessidades desse campo.

Trazendo esses cenários anteriores para o Ensino de Ciências, e considerando que em termos de parâmetros curriculares nacionais, o ensino da Biossegurança ainda não foi contemplado, aparecendo algumas vezes como tema transversal e atrelado ao campo da Segurança no Trabalho, e acentuando a contradição existente, já que em termos de mídia, a Biossegurança ocupa lugar de destaque, em função das suas imbricações sociais, éticas, econômicas, religiosas, ideológicas, técnicas, entre outras, além do fato, de que o governo brasileiro por meio de algumas agências de fomento como o CNPq e FINEP, estarem incentivando e apoiando projetos de pesquisa na área, acreditamos que as práticas educativas relacionadas ao Ensino de Ciências podem contribuir de forma significativa para o aculturamento da Biossegurança em todos os níveis de ensino.

Em relação a isso, o grupo de estudos do CNPq "Educação Profissional em Biossegurança”, alocado na Escola Politécnica de Saúde Joaquim Venâncio/Fiocruz, em parceria com a Comissão de Biossegurança do Instituto Oswaldo Cruz/Fiocruz, e da Comissão de Biossegurança da Faculdade de Farmácia, Odontologia e Enfermagem da Universidade Federal do Ceará, vem obtendo resultados positivos na divulgação e produção do conhecimento em Biossegurança, por meio de projetos apoiados pelo CNPq.

Merece atenção, o crescente, embora ainda com pequena velocidade, número de artigos, dissertações e teses sobre o tema, não apenas na vertente técnica da Biossegurança, mas também, na vertente educativa (PEREIRA, 2010; PEREIRA et al., 2010; CARVALHO, 2008; NEVES, 2006; COSTA, 2005).

Em vista do exposto, o objetivo deste ensaio é tecer alguns comentários sobre a Biossegurança em Saúde no contexto do Ensino de Ciências, ressaltando implicações dessa temática na sociedade e como ações educativas podem contribuir para a sua melhor compreensão. 


\section{BIOSSEGURANÇA E ENSINO DE CIÊNCIAS}

No ensino básico não existe nenhuma atividade continuada que contemple esta necessidade. No ensino superior, nos cursos da área da saúde, apesar de esforços de algumas universidades, em alguns cursos, como os de medicina, odontologia, enfermagem, biologia, farmácia, e veterinária, ainda existe um grande abismo entre a magnitude do problema e a formação e capacitação de profissionais com compreensão adequada sobre a Biossegurança (COSTA e COSTA, 2010; COSTA e COSTA, 2007; ROCHA e FARTES, 2001).

As mudanças ocorridas no mundo do trabalho, principalmente em relação aos processos desenvolvidos na área da saúde, com a inclusão de novas tecnologias de diagnóstico e tratamento, o uso de novos produtos químicos, o acúmulo de resíduos perigosos, a exigência cada vez maior sobre os indivíduos que atuam nessas áreas, entre outros fatores, que têm acarretado agravos ocupacionais sérios, está trazendo à tona a necessidade de estudos sobre a formação em Biossegurança dos profissionais que trabalham nesses ambientes, e principalmente dos futuros profissionais, ou seja, os alunos.

Nessa linha, temos que reconhecer que o mundo da escola, seja no âmbito dos cursos técnicos ou superiores da área da saúde, por meio dos currículos de ciências que ainda permanecem defasados, e retratando a prática científica de forma distante da sociedade, da cultura e da vida cotidiana, além de outros fatores como, a desvalorização docente, conteúdos fragmentados, ausência de métodos inovadores de ensino, infraestrutura, muitas vezes inadequada, relações ocupacionais conflituosas (bullying, violência em sala de aula e arredores, entre outras), não está atendendo de forma satisfatória o mundo do trabalho.

Forgiarini e Auler (2009: p.400) acentuam que é marcante o distanciamento do mundo da escola para o mundo da vida (a nosso ver, expressão ampliada para o mundo do trabalho), e afirmam que na maioria das vezes, o mundo da escola "é um mundo fechado, isolado, com suas componentes disciplinares fragmentadas, representando ilhas que não dialogam entre si e nem possuem conexões com os problemas vividos pela comunidade escolar".

Meis (2002, p.11) falando sobre o desenvolvimento da ciência nos dois últimos séculos, aponta que:

As prioridades atribuídas às tecnologias modernas conflitam de forma contínua com valores humanos previamente estabelecidos, gerando o conflito humano-tecnológico. Uma das causas desse conflito reside na forma ultrapassada de ensinar nas escolas e universidades [...] ainda não aprendemos como ajustar o novo conhecimento ao modo de ensinar.

Em função disso, o mundo do trabalho busca suprir essas lacunas, planejando ações educativas, repetimos, voltadas exclusivamente para as suas necessidades, isto é, o objetivo maior passa a ser o adestramento, o que em relação à Biossegurança é totalmente incompatível, haja vista, a diversidade de imbricações que esse campo do conhecimento permeia, o que demanda processos educativos coerentes e voltados para a própria cidadania, e não apenas para atender aos interesses de algumas instituições.

Outro fator que vem contribuindo, de forma negativa, para o distanciamento da Biossegurança das práticas educativas formais, na área do Ensino de Ciências, por exemplo, é a compreensão ainda não adequada da maioria dos professores de ciências sobre esse campo do conhecimento.

Ramos e Silva (2007) e Reis (2004) consideram que a dificuldade de abordagem de temas complexos comdimensões sociais, científicas e tecnológicas, por professores de ciências, ainda é visível. Forgiarini e Auler (2009) apontam que temas complexos contemporâneos são pouco abordados nos currículos de cursos de licenciaturas. Watanabe et al. (2012) acentuam a necessidade de se discutir, no contexto escolar, tais temas (no artigo, essas autoras trabalham com temas ambientais), até porque a escola é o espaço estratégico e privilegiado para essas ações. 
Outro fator que também pode estar contribuindo para isso, é a ausência de discussão da Biossegurança nos livros didáticos de ciências. Costa et al. (2008) estudaram a inserção desse campo do conhecimento em 26 livros didáticos de ciências (química, biologia e física), utilizados no ensino médio e publicados entre 1997 e 2005, período em que estava vigente a Lei № 8.974 (primeira Lei de Biossegurança), promulgada em 1995 e revogada em março de 2005. Os resultados dessa pesquisa mostraram uma ausência preocupante da biossegurança nos livros selecionados.

Um ponto ainda crítico, quando se fala de Biossegurança, é a questão da sua profissionalização, que é um processo que normalmente se inicia através da identificação de uma necessidade social não atendida (COSTA e COSTA, 2012). Não existem no Brasil, cursos técnicos e superiores sobre Biossegurança, portanto, não temos profissionais desse campo, mas sim, profissionais das mais diversas graduações, que atuam em atividades inerentes à Biossegurança, ou seja, ela tornou-se uma ocupação. Em termos gerenciais isso é crítico, porque esses profissionais atuam nas questões relativas à Biossegurança nas suas "horas vagas", ou seja, na grande maioria das vezes, não existe uma dedicação exclusiva a essas atividades (COSTA e COSTA, 2012).

\section{CONSIDERAÇÕES FINAIS}

A Biossegurança, de forma geral, pelas suas questões controversas, que são também questões sociais, coloca em embate não apenas as comunidades científicas, como a própria sociedade. Dessa forma, a Biossegurança, enquanto atividade intencionalizada, é influenciada pelo meio e permeada de relações ideológicas e de poder, que variam de sociedade para sociedade, e que influenciam, sobremaneira, seu processo de ensino - aprendizagem.

Nesta perspectiva, o Ensino de Ciências, pode ser um forte aliado da Biossegurança, principalmente no nível da pós-graduação, assumindo papel de destaque, já que a partir das suas produções acadêmicas, muitas das lacunas existentes, poderão ser preenchidas, ou, melhor compreendidas. Por exemplo: como elaborar currículos adequados aos temas complexos? Como propiciar aos professores de ciências uma melhor compreensão da Biossegurança? Quais as percepções de alunos e docentes de cursos da área da saúde sobre a Biossegurança? Como incluir a Biossegurança nos livros didáticos de ciências? São questionamentos, ou melhor, oportunidades acadêmicas, que se aplicam a todos os níveis de ensino, e que podem ser transformadas em temas de pesquisa, contribuindo, dessa forma, para que o Ensino de Ciências se insira na discussão de temas complexos / polêmicos, com ganhos acentuados para a sociedade, e para a introdução da Biossegurança no itinerário educativo brasileiro.

\section{REFERÊNCIAS}

BORBA, C.M.; COSTA, M.A.F.; PEREIRA, M.E.C.; CARVALHO, P.R.; VALLE, S. Biossegurança e Boas Práticas Laboratoriais. In: MOLINARO, E.; CAPUTO, L.; AMENDOEIRA, R. Conceitos e Métodos para Formação de Profissionais em Laboratórios de Saúde. V.1. Rio de Janeiro: EPSJV/IOC, 2009.

CARVALHO, P.R. O olhar docente sobre a biossegurança no ensino de ciências: um estudo em escolas da rede pública do Rio de Janeiro. Tese (Doutorado) - Instituto Oswaldo Cruz / Fiocruz, Rio de Janeiro, 2008.

COSTA, M.A.F. Construção do Conhecimento em Saúde: o ensino de biossegurança em cursos de nível médio na Fundação Oswaldo Cruz. Tese (Doutorado) - Instituto Oswaldo Cruz / Fiocruz, Rio de Janeiro, 2005.

COSTA, M.A.F.; COSTA, M.F.B. Entendendo a biossegurança: epistemologia e competências para a área de saúde. Rio de Janeiro: Publit, 2012.

COSTA, M.A.F.; COSTA, M.F.B. Educação em biossegurança: contribuições pedagógicas para a formação profissional em saúde. Ciência e Saúde Coletiva, v.15, supl.1, Rio de Janeiro, 2010, pp. 1741-1750. 
COSTA, M.A.F.; COSTA, M.F.B. A Biossegurança na Formação Profissional em Saúde: ampliando o debate. In: PEREIRA, I.B.; RIBEIRO, C.G. (Coord.). Estudos de Politecnia e Saúde. V.2. Rio de Janeiro: EPSJV, 2007.

COSTA, M.A.F.; COSTA, M.F.B. Educação e competências em biossegurança. Revista Brasileira de Educação Médica, 2004; 28(1): pp. 46-50.

COSTA, M. A. F.; COSTA, M.F.B.; MURITO, M.M.C.; CARVALHO, P.R.; PEREIRA, M.E.C. Biossegurança no ensino médio: uma discussão preliminar sobre conteúdos em livros didáticos de ciências e práticas docentes. In: 1 SEMINÁRIO NACIONAL DE EDUCAÇÃO PROFISSIONAL E TECNOLÓGICA，2008, Belo Horizonte.

FORGIARINI, M.S.; AULER, D.A. A abordagem de temas polêmicos na educação de jovens e adultos: o caso do "florestamento" no Rio Grande do Sul. Revista Electrónica de Enseñanza de las Ciencias, v.8, n.2, 2009, pp. 399-421.

FOUREZ, G. A construção das ciências: introdução à filosofia e à ética das ciências. São Paulo: Editora UNESP, 1995.

MEIS, L. Ciência, Educação e o conflito humano-tecnológico. São Paulo: SENAC, 2002.

NEVES, T.P. A produção científica sobre biossegurança no Brasil. Dissertação (Mestrado) - Escola Nacional de Saúde Pública Sérgio Arouca / Fiocruz, Rio de Janeiro, 2006.

PEREIRA, M.E.C. Um olhar sobre a capacitação em biossegurança no Instituto Oswaldo Cruz: o processo de transformação. Dissertação (Mestrado) - Instituto Oswaldo Cruz / Fiocruz, Rio de Janeiro, 2010.

PEREIRA, M.E.C.; COSTA, M.A.F.; BORBA, C.M.; JURBERG, C. Construção do conhecimento em biossegurança: uma revisão da produção acadêmica nacional na área de saúde (1989-2009). Saúde e Sociedade, 2010; v.19, n.2, São Paulo, 2010, pp. 395-404.

RAMOS, M. B.; SILVA, H. C. Para pensar as controvérsias científicas em aulas de ciências. Ciência \& Ensino, Campinas, v. 1, 2007, pp. 1-16.

REIS, P. Controvérsias sócio-científicas: discutir ou não discutir? Tese (Doutorado) - Faculdade de Educação da Universidade de Lisboa, Lisboa, 2004.

ROCHA, S.S.; FARTES, V.L.B. Biossegurança e competência profissional: um novo desafio para a educação no setor saúde. Caderno CRH, n.34, 2001, pp. 125-140.

TEIXEIRA, P.; VALLE, S. Biossegurança: uma abordagem multidisciplinar. 2. Edição. Fiocruz: Rio de Janeiro, 2010.

WATANABE, G.; STRIEDER, R.B.; GEHLEN, S.T. Desafios e possibilidades para a abordagem de temas ambientais em aulas de Física. Revista Brasileira de Pesquisa em Educação em Ciências, v. 12, n.1, 2012, pp. 205-222. 